\title{
Use of Gabapentin, Esmolol or Their Combination to Attenuate Haemodynamic Response to Laryngoscopy and Intubation
}

\section{Shrestha GS, Marhatta MN, Amatya R}

Department of Anaesthesiology

Maharajgunj Medical Campus

Tribhuvan University Teaching Hospital

Maharajgunj, Kathmandu, Nepal

\section{Corresponding Author}

Gentle Sunder Shrestha

Department of Anaesthesiology

Maharajgunj Medical Campus

Tribhuvan University Teaching Hospital

Maharajgunj, Kathmandu, Nepal

Email: gentlesunder@hotmail.com

\section{Citation}

Shrestha GS, Marhatta MN, Amatya R. Use of Gabapentin, Esmolol, or Their Combination to Attenuate Haemodynamic Response to Laryngoscopy and Intu bation. Kathmandu Univ Med J 2011;36(4):238-43.

\author{
ABSTRACT \\ Background \\ Laryngoscopy and intubation increases blood pressure and heart rate. \\ Objective
}

The study aims to investigate the effect and safety of gabapentin, esmolol or their combination on the haemodynamic response to laryngoscopy and intubation.

\section{Methods}

A total of 72 patients undergoing elective surgery were randomly allocated to one of the four groups. First study drug was administered orally as gabapentin $1200 \mathrm{mg}$ or placebo. Second study drug was administered intravenously as esmolol $1.5 \mathrm{mg} /$ $\mathrm{kg}$ or normal saline. Heart rate, rate pressure product, systolic blood pressure and mean arterial pressure were recorded at baseline and at zero, one, three and five minutes after tracheal intubation.

\section{Results}

Baseline values were compared with the values at various time intervals within the same group. In group PE (placebo, esmolol), there was significant decrease in heart rate and rate pressure product at five minutes. In group GN (gabapentin, normal saline), there was significant decrease in systolic blood pressure and mean arterial pressure at five minutes. In group GE (gabapentin, esmolol), there was significant decrease in heart rate at zero, three and five minutes. Systolic blood pressure, mean arterial pressure and rate pressure product was significantly lower at three and five minutes. In group PN (placebo, normal saline), there was significant increase in heart rate at zero, one, three and five minutes; systolic blood pressure at zero and one minutes; mean arterial pressure at zero and one minutes \& rate pressure product at zero, one and three minutes. In group GN (gabapentin, normal saline), there was significant increase in heart rate at zero, one and three minutes \& rate pressure product at zero, one and three minutes. In group PE (placebo, esmolol), there was significant increase in systolic blood pressure at zero and one minutes \& mean arterial pressure at zero and one minutes. However, in group GE (gabapentin, esmolol) none of the variables showed statistically significant increase at any time.

Inter-group comparison was made for each time point. At zero minute, there was significant difference in heart rate between groups PN and GE, GN and PE \& GN and GE Significant difference was also noted in rate pressure product between $P N$ and $\mathrm{GE}$ at zero minute. At one minute there was difference in heart rate between PN and $P E, P N$ and GE, GN and PE \& between GN and GE. Significant difference was observed in rate pressure product between $\mathrm{PN}$ and $\mathrm{PE} \&$ between $\mathrm{PN}$ and GE at one minute. No significant side effects of the study drugs were observed.

\section{Conclusions}

Combination of gabapentin and esmolol in this study design is safe and better attenuates both the pressor and tachycardic response to laryngoscopy and intubation, than either agent alone.

\section{KEYWORDS}

attenuation of haemodynamic response, Esmolol, Gabapentin, laryngoscopy and intubation 


\section{INTRODUCTION}

Laryngoscopy and tracheal intubation are associated with hypertension, tachycardia and increased circulating

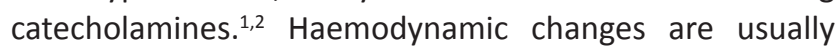
transient and without sequelae. However, in patients with pre-existing coronary artery disease, hypertension or cerebrovascular disease, these changes may precipitate myocardial ischaemia, arrhythmias, myocardial infraction and cerebral haemorrhage. .,4 $^{3}$

Various techniques have been studied to prevent or attenuate the haemodynamic response to laryngoscopy and intubation, such as omitting cholinergic medications, deepening of anaesthesia, pretreatment with nitroglycerine, beta-blockers, calcium channel blockers, gabapentin and opioids like fentanyl and remifentanil. ${ }^{5-12}$

Gabapentin was shown to be effective in decreasing postoperative analgesic consumption and pain, prevention of postoperative nausea and vomiting, reduction of postoperative delirium, preoperative anxiolysis and attenuation of haemodynamic response to laryngoscopy and intubation. ${ }^{10,13-17}$ This multimodal perioperative drug is a sturctural analog of $\gamma$-aminobutyric acid. It acts by decreasing the synthesis of neurotransmitter glutamate and by binding to $\alpha 2 \delta$ subunit of voltage dependent calcium channel. ${ }^{18,19}$ Action similar to calcium channel blockers may be responsible for blunting haemodynamic response to laryngoscopy and intubation. ${ }^{20}$

Esmolol is a $\beta 1$-adrenoceptor (cardioselective) blocker. It has a very short diffusion (two minutes) and elimination half-life (nine minutes). Peak effects with bolus injections of esmolol are seen in one to two minutes. ${ }^{21}$ Several studies showed esmolol to be effective in blunting the pulse rate response to laryngoscopy and intubation, but blood pressure response was blunted only at higher dose. ${ }^{22-25}$

Gabapentin is a multimodal perioperative drug. It has a favourable side effect profile and has less interaction with other drugs. ${ }^{26,27}$ There are no studies comparing the efficacy of gabapentin and esmolol to blunt the haemodynamic response to laryngocopy and intubation. So this study was conducted to compare the efficacy and safety of these agents alone or in combination.

\section{METHODS}

Patients scheduled for elective surgery with American Society of Anaesthesiologists (ASA) physical status I and II, weighing 40 to $70 \mathrm{kgs}$ and with age 18 to 65 years were enrolled in the study. The study was conducted in Tribhuvan University Teaching Hospital between January to March 2011. Patients with pre-existing cardiopulmonary disease, with contraindications or known hypersensitivity to study drug or on antihypertensive medications or drugs with effect on central nervous system were excluded. Patients with anticipated difficult airway and with duration of laryngoscopy more than 30 seconds or with more than one attempt at intubation were also excluded from the study.

Patients were randomly assigned to one of the four study groups PN (placebo normal saline), PE (placebo, esmolol), GN (gabapentin, normal saline) or GE (gabapentin, esmolol) using a sealed envelope method. In each group 18 patients were enrolled. First study drug was administered orally two hours before induction. It was placebo capsules for group $\mathrm{PN}$ and PE. Two gabapentin capsules with $600 \mathrm{mg}$ in each were administered as first study drug in group GN and GE. Second study drug was administered intravenously two minutes before laryngoscopy and intubation. It was $11 \mathrm{ml}$ of normal saline in group PN and GN. Esmolol $1.5 \mathrm{mg} / \mathrm{kg}$, diluted to $11 \mathrm{ml}$, was given as second study drug in group $\mathrm{PE}$ and GE.

Patients were fasted for six hours before study. Any side effects of first study drug like nausea and vomiting, dizziness, somnolence, ataxia and headache were noted before induction. Ringer's lactate seven milliliters per kilogram was given intravenously before induction. Heart rate (HR), systolic blood pressure (SBP) and diastolic blood pressure (DBP) were noted at baseline, after induction, immediately after intubation (zero minute) and at one, three and five minutes after intubation. Mean arterial pressure (MAP) and rate pressure product (RPP) were calculated from these parameters. Pethidine $0.75 \mathrm{mg} / \mathrm{kg}$ was given as an analgesic. Patients were induced with propofol 2 to 2.5 $\mathrm{mg} / \mathrm{kg}$ and vecuronium $0.1 \mathrm{mg} / \mathrm{kg}$ was given as a muscle relaxant. Second study drug was administered two minutes after giving vecuronium. HR less than 45 beats/min was treated with Inj. atropine in increments of $0.3 \mathrm{mg}$ and fall in SBP of more than $30 \%$ below the baseline for longer than 60 seconds was treated with Inj. mephentermine in increments of three milligrams. Increase in SBP of more than $30 \%$ of baseline for longer than 60 seconds or HR of more than 130 beats/min for longer than 60 seconds was managed by increasing the inspired Halothane concentration in increments of $0.5 \%$. Surgical incision was delayed for five minutes after intubation.

ANOVA was used with Bonferroni test for group differences. Paired $t$ test was used for comparison with baseline. Independent t test was use for comparison between the groups. Chi square test was used for studying association between categorical variables. Statistical analyses were done with SPSS 17.0 package program for Windows.

Sample size (72 patients) was calculated to ensure power of 0.80 using Russell-Lenth's power/sample-size calculator. ${ }^{28}$ Pretest of 50 cases was done for sample size calculation.

\section{RESULTS}

Demographic variables did not differ significantly between the groups (table 1).

Within individual groups, baseline haemodynamic variables were compared with variables at various time intervals 
Table 1. Patient characteristics. (Values are Mean \pm SD)

\begin{tabular}{llllll} 
Variable & Group PN & Group PE & Group GN & Group GE & p value \\
\hline Age $(\mathrm{yrs})$ & $32.11 \pm 9.74$ & $31.11 \pm 12.26$ & $37.78 \pm 12.56$ & $34.00 \pm 10.66$ \\
Weight $(\mathrm{kg})$ & $56.67 \pm 7.17$ & $51.61 \pm 6.99$ & $53.72 \pm 9.40$ & $57.11 \pm 8.25$ & 0.14 \\
\hline
\end{tabular}

Table 2. Comparison of haemodynamic variables with baseline.

\begin{tabular}{|c|c|c|c|c|}
\hline & Group PN & Group GN & Group PE & Group GE \\
\hline & Mean $\pm S D$ & Mean $\pm S D$ & Mean $\pm S D$ & Mean \pm SD \\
\hline & \multicolumn{4}{|c|}{ Heart Rate (beats/min) } \\
\hline Baseline & $77.72 \pm 13.62$ & $80.17 \pm 14.54$ & $87.22 \pm 11.72$ & $87.94 \pm 14.51$ \\
\hline Induction & $79.83 \pm 15.70$ & $82.56 \pm 18.65$ & $81.78 \pm 11.46$ & $87.67 \pm 14.74$ \\
\hline Intubation & $94.39 \pm 15.06^{* *}$ & $100.17 \pm 19.33^{* *}$ & $84.78 \pm 13.37$ & $82.78 \pm 14.88^{\#}$ \\
\hline $1 \mathrm{~min}$ & $101.28 \pm 16.73^{* *}$ & $96.28 \pm 14.82^{* *}$ & $83.78 \pm 11.99$ & $84.17 \pm 17.15$ \\
\hline $3 \mathrm{~min}$ & $93.22 \pm 14.86^{* *}$ & $92.50 \pm 11.92^{*}$ & $84.44 \pm 14.51$ & $82.83 \pm 17.21 \#$ \\
\hline \multirow[t]{2}{*}{$5 \mathrm{~min}$} & $85.83 \pm 15.92^{*}$ & $81.83 \pm 16.72$ & $81.72 \pm 14.57^{\#}$ & $78.89 \pm 13.08^{\# \#}$ \\
\hline & \multicolumn{4}{|c|}{ Systolic Blood Pressure ( $\mathrm{mm}$ of $\mathrm{Hg}$ ) } \\
\hline Baseline & $117.28 \pm 18.08$ & $125.94 \pm 15.90$ & $117.67 \pm 14.78$ & $128.56 \pm 16.96$ \\
\hline Induction & $105.78 \pm 13.22$ & $112.56 \pm 17.98$ & $109.67 \pm 13.99$ & $117.06 \pm 18.57$ \\
\hline Intubation & $134.50 \pm 17.91^{* *}$ & $123.44 \pm 17.33$ & $129.94 \pm 19.53^{*}$ & $125.50 \pm 20.67$ \\
\hline $1 \mathrm{~min}$ & $134.50 \pm 18.87^{* *}$ & $124.06 \pm 14.77$ & $128.94 \pm 15.83^{* *}$ & $122.78 \pm 21.06$ \\
\hline $3 \mathrm{~min}$ & $122.61 \pm 19.55$ & $121.44 \pm 16.15$ & $120.78 \pm 14.39$ & $116.67 \pm 17.61^{\#}$ \\
\hline \multirow[t]{2}{*}{$5 \mathrm{~min}$} & $116.28 \pm 19.08$ & $116.17 \pm 16.43^{\#}$ & $113.06 \pm 14.07$ & $113.50 \pm 19.36^{\#}$ \\
\hline & \multicolumn{4}{|c|}{ Mean Arterial Pressure ( $\mathrm{mm}$ of $\mathrm{Hg}$ ) } \\
\hline Baseline & $88.05 \pm 13.08$ & $94.28 \pm 9.94$ & $88.96 \pm 11.56$ & $96.85 \pm 15.19$ \\
\hline Induction & $79.04 \pm 11.14$ & $84.11 \pm 13.30$ & $81.81 \pm 12.52$ & $87.87 \pm 15.61$ \\
\hline Intubation & $103.76 \pm 15.20^{* *}$ & $96.48 \pm 12.28$ & $102.72 \pm 16.77^{*}$ & $95.06 \pm 16.49$ \\
\hline $1 \mathrm{~min}$ & $101.98 \pm 14.69^{*}$ & $95.20 \pm 11.76$ & $98.43 \pm 14.64^{*}$ & $93.22 \pm 17.23$ \\
\hline $3 \mathrm{~min}$ & $92.06 \pm 14.55$ & $93.04 \pm 11.03$ & $93.52 \pm 13.68$ & $89.30 \pm 16.45^{\#}$ \\
\hline \multirow[t]{2}{*}{$5 \mathrm{~min}$} & $87.39 \pm 17.05$ & $87.24 \pm 9.86^{\#}$ & $86.35 \pm 13.98$ & $86.02 \pm 16.27^{\#}$ \\
\hline & \multicolumn{4}{|c|}{ Rate Pressure Product (beats . $\mathrm{mm} \mathrm{Hg} / \mathrm{min}$ ) } \\
\hline Baseline & $9233.11 \pm 2817.85$ & $9994.67 \pm 1733.24$ & $10313.89 \pm 2262.02$ & $11456.17 \pm 3012.55$ \\
\hline Induction & $8432.94 \pm 1931.33$ & $9141.56 \pm 1861.94$ & $8967.72 \pm 1747.33$ & $10416.33 \pm 2998.95$ \\
\hline Intubation & $12832.44 \pm 3281.53^{* *}$ & $12311.67 \pm 2841.93^{* *}$ & $11118.44 \pm 3029.77$ & $10537.06 \pm 3222.62$ \\
\hline $1 \mathrm{~min}$ & $13670.11 \pm 3402.72^{* *}$ & $11973.89 \pm 2548.82^{* *}$ & $10879.72 \pm 2539.17$ & $10557.39 \pm 3473.41$ \\
\hline $3 \mathrm{~min}$ & $11471.89 \pm 2933.95^{* *}$ & $11231.56 \pm 2123.22^{*}$ & $10276.11 \pm 2628.31$ & $9879.44 \pm 3368.19^{\#}$ \\
\hline $5 \mathrm{~min}$ & $10040.17 \pm 2605.75$ & $9525.22 \pm 2581.54$ & $9282.83 \pm 2253.37^{\#}$ & $9131.39 \pm 2823.11^{\# \#}$ \\
\hline
\end{tabular}

$* p<0.05$ (increase), $* * p<0.01$ (increase), $\# p<0.05$ (decrease), \#\# $p<0.01$ (decrease)

(Table 2). In group $P E$, there was significant decrease in $\mathrm{HR}$ at five minutes $(p<0.05)$ \& RPP at five minutes $(p<0.05)$. In group GN, there was significant decrease in $\mathrm{SBP}$ at five minutes $(p<0.05)$ \& MAP at five minutes $(p<0.05)$. In group $\mathrm{GE}$, there was significant decrease in $\mathrm{HR}$ at zero minute $(p<0.05)$, three minutes $(p<0.05)$ and five minutes $(p<0.01)$; RPP at three minutes $(p<0.05)$ and five minutes $(p<0.01)$; SBP at three minutes $(p<0.05)$ and five minutes $(p<0.05)$ \& MAP at three minutes $(p<0.05)$ and five minutes $(p<0.05)$.

In group $\mathrm{PN}$, there was significant increase in $\mathrm{HR}$ at zero minute $(p<0.01)$, one minute $(p<0.01)$, three minutes $(p<0.01)$ and five minutes $(p<0.05)$; SBP at zero minute $(p<0.01)$ and one minute $(p<0.01)$; MAP at zero minute

$(p<0.01)$ and one minute $(p<0.05) \&$ RPP at zero minute $(p<0.01)$, one minute $(p<0.01)$ and three minutes $(p<0.01)$. In group $\mathrm{GN}$, there was significant increase in $\mathrm{HR}$ at zero minute $(p<0.01)$, one minute $(p<0.01)$ and three minutes $(p<0.05)$ \& RPP at zero minute $(p<0.01)$, one minute $(p<0.01)$ and three minutes $(p<0.05)$. In group $P E$, there was significant increase in SBP at zero minute $(p<0.05)$ and one minute $(p<0.01)$ \& MAP at zero minute $(p<0.05)$ and one minute $(p<0.05)$. However, in group $\mathrm{GE}$, none of the variables showed statistically significant increase at any time.

Inter-group comparison was made for each time point 
Table 3. Inter-group comparison for each time point.

\begin{tabular}{|c|c|c|c|c|}
\hline & Group PN & Group GN & Group PE & Group GE \\
\hline & Mean $\pm S D$ & Mean $\pm S D$ & Mean $\pm S D$ & Mean $\pm S D$ \\
\hline & \multicolumn{4}{|l|}{ Baseline } \\
\hline Heart Rate (beats/min) & $77.72 \pm 13.62$ & $80.17 \pm 14.54$ & $87.22 \pm 11.72$ & $87.94 \pm 14.51$ \\
\hline SBP (mm Hg) & $117.28 \pm 18.08$ & $125.94 \pm 15.90$ & $117.67 \pm 14.78$ & $128.56 \pm 16.96$ \\
\hline MAP (mm Hg) & $88.06 \pm 13.08$ & $94.28 \pm 9.94$ & $88.96 \pm 11.56$ & $96.85 \pm 15.19$ \\
\hline \multirow[t]{2}{*}{ RPP (beats.mmHg/min) } & $9233.11 \pm 2817.85$ & $9994.67 \pm 1733.24$ & $10313.89 \pm 2262.02$ & $11456.17 \pm 3012.55$ \\
\hline & \multicolumn{4}{|l|}{ Induction } \\
\hline Heart Rate (beats/min) & $79.83 \pm 15.70$ & $82.56 \pm 18.65$ & $81.78 \pm 11.46$ & $87.67 \pm 14.74$ \\
\hline $\mathrm{SBP}(\mathrm{mm} \mathrm{Hg})$ & $105.78 \pm 13.22$ & $112.56 \pm 17.98$ & $109.67 \pm 13.99$ & $117.06 \pm 18.57^{*}$ \\
\hline MAP (mm Hg) & $79.04 \pm 11.14$ & $84.11 \pm 13.30$ & $81.81 \pm 12.52$ & $87.87 \pm 15.61$ \\
\hline \multirow[t]{2}{*}{ RPP (beats. $\mathrm{mmHg} / \mathrm{min}$ ) } & $8432.94 \pm 1931.33$ & $9141.56 \pm 1861.94$ & $8967.72 \pm 1747.33$ & $10416.33 \pm 2998.95^{*}$ \\
\hline & \multicolumn{4}{|l|}{ Intubation } \\
\hline Heart Rate (beats/min) & $94.39 \pm 15.06$ & $100.17 \pm 19.33$ & $84.78 \pm 13.37 ! !$ & $82.78 \pm 14.88^{* \$ \$}$ \\
\hline $\mathrm{SBP}(\mathrm{mm} \mathrm{Hg})$ & $134.50 \pm 17.91$ & $123.44 \pm 17.33$ & $129.94 \pm 19.53$ & $125.50 \pm 20.67$ \\
\hline MAP (mm Hg) & $103.76 \pm 15.20$ & $96.48 \pm 12.28$ & $102.72 \pm 16.77$ & $95.06 \pm 16.49$ \\
\hline \multirow[t]{2}{*}{ RPP (beats.mmHg/min) } & $12832.44 \pm 3281.53$ & $12311.67 \pm 2841.93$ & $11118.44 \pm 3029.77$ & $10537.06 \pm 3222.62^{*}$ \\
\hline & \multicolumn{4}{|l|}{1 minute } \\
\hline Heart Rate (beats/min) & $101.28 \pm 16.73$ & $96.28 \pm 14.82$ & $83.78 \pm 11.99^{\wedge \wedge ! !}$ & $84.17 \pm 17.15^{* * \$}$ \\
\hline $\mathrm{SBP}(\mathrm{mm} \mathrm{Hg})$ & $134.50 \pm 18.87$ & $124.06 \pm 14.77$ & $128.94 \pm 15.83$ & $122.78 \pm 21.06$ \\
\hline MAP (mm Hg) & $101.98 \pm 14.69$ & $95.20 \pm 11.76$ & $98.43 \pm 14.64$ & $93.22 \pm 17.23$ \\
\hline \multirow[t]{2}{*}{ RPP (beats.mmHg/min) } & $13670.11 \pm 3402.72$ & $11973.89 \pm 2548.82$ & $10879.72 \pm 2539.17^{\wedge \wedge}$ & $10557.39 \pm 3473.41^{*}$ \\
\hline & \multicolumn{4}{|l|}{3 minute } \\
\hline Heart Rate (beats/min) & $93.22 \pm 14.86$ & $92.50 \pm 11.92$ & $84.44 \pm 14.51$ & $82.83 \pm 17.21$ \\
\hline $\mathrm{SBP}(\mathrm{mm} \mathrm{Hg})$ & $122.61 \pm 19.55$ & $121.44 \pm 16.15$ & $120.78 \pm 14.39$ & $116.67 \pm 17.61$ \\
\hline MAP (mm Hg) & $92.06 \pm 14.55$ & $93.04 \pm 11.03$ & $93.52 \pm 13.68$ & $89.30 \pm 16.45$ \\
\hline \multirow[t]{2}{*}{ RPP (beats.mmHg/min) } & $11471.89 \pm 2933.95$ & $11231.56 \pm 2123.22$ & $10276.11 \pm 2628.31$ & $9879.44 \pm 3368.19$ \\
\hline & \multicolumn{4}{|l|}{5 minute } \\
\hline Heart Rate (beats/min) & $85.83 \pm 15.92$ & $81.83 \pm 16.72$ & $81.72 \pm 14.57$ & $78.89 \pm 13.08$ \\
\hline $\mathrm{SBP}(\mathrm{mm} \mathrm{Hg})$ & $116.28 \pm 19.08$ & $116.17 \pm 16.43$ & $113.06 \pm 14.07$ & $113.50 \pm 19.36$ \\
\hline MAP (mm Hg) & $87.39 \pm 17.05$ & $87.24 \pm 9.86$ & $86.35 \pm 13.98$ & $86.02 \pm 16.27$ \\
\hline RPP (beats.mmHg/min) & $10040.17 \pm 2605.75$ & $9525.22 \pm 2581.54$ & $9282.83 \pm 2253.37$ & $9131.39 \pm 2823.11$ \\
\hline
\end{tabular}

* p <0.05 (Group PN Vs Group GE), ** p<0.01 (Group PN Vs Group GE), \$ p<0.05 (Group GN Vs GE), \$\$ p<0.01 (Group GN Vs Group GE), ^^ p<0.01 (Group PN Vs PE), !! $p<0.01$ (Group GN Vs PE)

(Table 3). At zero minute, there was significant difference $(p<0.05)$ in HR between groups PN and GE $(94.39 \pm 15.06 \mathrm{Vs}$ 82.78 \pm 14.88$), \mathrm{GN}$ and PE $(100.17 \pm 19.33$ Vs $84.78 \pm 13.37)$ \& between GN and GE $(100.17 \pm 19.33$ Vs $82.78 \pm 14.88)$. Significant difference $(p<0.05)$ was also noted in RPP between PN and GE (12832.44 \pm 3281.53 Vs $10537.06 \pm 3222.62)$ at zero minute. At one minute there was difference $(p<0.05)$ in HR between PN and PE (101.28 \pm 16.72 Vs 83.78 \pm 11.99$)$, $P N$ and $G E(101.28 \pm 16.72$ Vs $84.17 \pm 17.15), G N$ and $P E$ (96.28 \pm 14.82 Vs $83.78 \pm 11.99)$ \& between $G N$ and $G E$ (96.28 \pm 14.82 Vs $84.17 \pm 17.15)$. Significant difference $(p<0.05)$ was observed in RPP between $P N$ and PE $(13670.11 \pm 3402.72$ Vs 10879.72 \pm 2539.17$)$ \& between $P N$ and GE (13670.11 \pm 3402.72 Vs $10557.39 \pm 3473.41)$ at one minute.

There was no incidence of nausea and vomiting, respiratory depression, dizziness, somnolence, ataxia and headache before induction of anaesthesia. One patient in Group PE developed bradycardia with heart rate upto 40 beats per minute, 25 minutes after administering the second study drug. It was treated with Inj. Atropine $0.3 \mathrm{mg}$. None of the patients needed Mephentermine for correction of hypotension.

\section{DISCUSSION}

To attenuate the pressor response to laryngoscopy and intubation, studies were done on gabapentin at various doses. ${ }^{10,17,29-31}$ Results are variable and most of the studies showed predominantly blood pressure attenuating effect of gabapentin. ${ }^{10,29-31} \mathrm{~A}$ meta-analysis on the use of gabapentin for postoperative analgesia showed the dose of $1200 \mathrm{mg}$ to be more effective than the dose of $300 \mathrm{mg}$ or $400 \mathrm{mg}$ for reducing postoperative opioid consumption. ${ }^{32}$ Moreover, a 
single $1200 \mathrm{mg}$ dose before surgery was found to reduce the incidence of postoperative nausea and vomiting. ${ }^{33,34}$ Gabapentin was found to be safe and devoid of significant side effects. So, a single preoperative dose of $1200 \mathrm{mg}$ was chosen in our study.

Esmolol is effective in attenuating the haemodynamic response in a dose dependent manner. ${ }^{35}$ When used in a dose of $1.5 \mathrm{mg} / \mathrm{kg}$, it was safe and predominantly suppressed the heart rate response..$^{22,36,37}$ So this dose was used in our study.

When compared with baseline values, in Group GN, there was significant increase in heart rate, but the systolic blood pressure was decreased at five and 10 minutes and mean arterial pressure was decreased at five minutes. The findings are consistent with the study by Kumari I and colleagues. ${ }^{30}$ As in our study, Kaya FN and colleagues did not find gabapentin to be effective to blunt the heart rate response, but blood pressure response was better attenuated, probably due to use of Fentanyl before intubation in their study. ${ }^{29}$

In Group PE, blood pressure increased at intubation and one minute, but the heart rate and rate pressure product decreased at five and 10 minutes. Findings are consitent with the study by Ugur B et al. ${ }^{22}$ Similarly, in a study by Rathore $A$ and colleagues, heart rate response was blunted at the dose of 50 and $100 \mathrm{mg} .{ }^{25}$ Blood pressure response was blunted only at the dose of $150 \mathrm{mg}$.

In Group GE, when compared with baseline, there was no significant increase in variables at any time. There was significant decrease in heart rate at intubation, three, five and 10 minutes. Systolic blood pressure, mean arterial pressure and rate pressure product was decreased at three, five and 10 minutes.

Comparison between the groups showed significant decrease in heart rate, systolic blood pressure and rate pressure product at various times when Group GE was compared with Group PN and GN. Also, there was significant reduction in heart rate and rate pressure product in Group PE when compared with Group PN and GN. Except for an episode of bradycardia in Group PE, treated with Inj. Atropine, other significant adverse effects were not noted.

There are few limitations of this study. Patients with ASA physical status I and II were enrolled in the study, so the results cannot be generalized to the patients with higher ASA status. Fixed dose of gabapentin and esmolol were used, so further studies may help find the optimal safe dose. The study was conducted in a single centre. A multicentered larger study may be more informative.

\section{CONCLUSION}

Combination of gabapentin and esmolol in this study design is safe and better attenuates both the heart rate and blood pressure response to laryngoscopy and intubation, than either agent alone.

\section{ACKNOWLEDGEMENT}

I want to acknowledge my colleagues Dr. Diptesh Aryal, Dr. Ashish G Amatya, Dr. Bibhush Shrestha, Dr. Madindra Basnet and Dr. Nitu Agrawal for helping me to collect data during the study.

\section{REFERENCES}

1. King BD, Harris LC, Greifenstein FE, Elder JD, Dripps RD. Reflex circulatory responses to direct laryngoscopy and tracheal intubation performed during general anesthesia. Anesthesiology 1951; 12: 55666.

2. Shribman AJ, Smith G, Achola KJ. Cardiovascular and catecholamine response to laryngoscopy with and without tracheal intubation. $\mathrm{Br} J$ Anaesth 1987; 59: 295-9.

3. Roy WL, Edelist G, Gilbert B. Myocardial ischemia during noncaridac surgical procedures in patients with coronary artery disease. Anesthesiology 1979;51: 393-7.

4. Fox EJ, Sklar GS, Hill CH, Villanueva R, King BD. Complications related to the pressor response to endotracheal intubation. Anesthesiology 1977;47:524-5.

5. Fassoulaki A, Kaniaris P. Does atropine premedication affect the cardiovascular response to laryngoscopy and intubation? Br J Anaesth 1982;54:1065-8.

6. Kovac AL. Controlling the hemodynamic response to laryngoscopy and endotracheal intubation. J Clin Anesth 1996;8:63-79.

7. Fassoulaki A, Kaniaris P. Intranasal administration of nitroglycerine attenuates the pressor response to laryngoscopy and intubation of the trachea. Br J Anaesth 1983;55:49-52.

8. Vucevic M, Purdy GM, Ellis FR. Esmolol hydrochloride for management of the cardiovascular stress response to laryngoscopy and tracheal intubation. Br J Anaesth 1992;68:529-30.

9. Mikawa K, Ikegaki J, Maekawa N, Goto R, Kaetsu H, Obara H. The effect of diltiazem on the cardiovascular response to tracheal intubation. Anaesthesia 1990;45:289-93.

10. Fassoulaki A, Melemeni A, Paraskeva A, Petropoulos G. Gabapentin attenuates the pressor response to direct laryngoscopy and tracheal intubation. Br J Anaesth 2006; 96: 769-73.

11. Adachi YU, Satomoto M, Higuchi $H$, Watanabe K. Fentaly attenuates the hemodynamic response to endotracheal intubation more than the response to laryngoscopy. Anesth Analg 2002; 95: 233-7.

12. Thompson JP, Hall AP, Russell J, Cagney B, Rowbotham DJ. Effect of remifentanil on the haemodynamic response to orotracheal intubation. Br J Anaesth 1998;80:467-9.

13. Dahl JB, Mathiesen O, Moiniche S. Protective premedication, an option with gapabentin and related drugs? A review of gabapentin and pregabalin in the treatment of post-operative pain. Acta Anaesthesiol Scand 2004;48:1130-6.

14. Pandey CK, Priye S. Ambesh SP, Singh S, Singh U, Singh PK. Prophylactic gabapentin for prevention of postoperative nausea and vomiting in patients undergoing laparoscopic cholecystectomy: a randomized, double-blind, placebo-controlled study. J Postgrad Med 2006;52:97100.

15. Leung JM, Sands LP, Rico M, Petersen KL, Rowbotham MC, Dahl JB et al. Pilot clinical trial of gabapentin to decrease postoperative delirium in older patients. Neurology 2006;67:1251-3.

16. Rorarius MG, Mennander S, Suominen P, Rintala S, Puura A, Pirhonen $R$ et al. Gabapentin for the prevention of postoperative pain after vaginal hysterectomy. Pain 2004;110:175-81. 
17. Memis D, Turan A, Karamanlioglu B, Seker S, Ture M. Gabapentin reduces cardiovascular responses to laryngoscopy and tracheal intubation. Eur J Anaesth 2006;23:686-90.

18. Patel. Placebo controlled study of gabapentin treatment of panic disorder. Pain 2001; 90:217-26.

19. Gee NS, Brown JP, Dissanayake VU. The novel anticonvulsant drug, gabapentin, binds to the $\alpha 2 \delta$ subunit of a calcium channel. $J$ Biol Chem 1996;271:5768-76.

20. Sarantopoulos C, McCallum B, Kwok WM, Hogan Q. Gabapentin decreases membrane calcium currents in injured as well as in control mammalian primary afferent neurons. Reg Anesth Pain Med 2002;27:47-57.

21. Sintelos AL, Hulse J, Pritchett EL. Pharmacokinetics and pharmacodynamics of esmolol administered as an intravenous bolus. Clin Pharmacol Ther 1987;41:112-7.

22. Ugur B, Ogurlu M, Erdal G, Aydin ON, Gursoy F. Effects of esmolol, lidocaine and fentanyl on haemodynamic responses to endotracheal intubation. Clin Drug Invest 2007;27(4):269-77.

23. Singh H, Vichitvejpaisal P, Gaines GY, White PF. Comparative effects of lidocaine, esmolol, and nitroglycerine in modifying the hemodynamic response to laryngoscopy and intubation. Journal of Clinical Anesthesia 1995;7:5-8.

24. Miller DR, Martineau RJ, Wynands JE, Hill J. Bolus administration of esmolol for controlling the haemodynamic response to tracheal intubation: the Canadian multicentre trial. Can J Anaesth 1991;38:849-58.

25. Rathore A, Gupta HK, Tanwar GL, Rehman H. Attenuation of the pressure response to laryngoscopy and endotracheal intubation with different doses of esmolol. Indian J Anaesth 2002;46(6):449-52.

26. McLean MJ, Morrell MJ, Willmore LJ, Privitera MD, Faught RE, Holmes GL et al. Safety and tolerability of gabapentin as adjunctive therapy in a large, multicenter study. Epilepsia 1999;40:965-72.

27. Busch JA, Radulovic LL, Bockbrader HN. Effect of Maalox TC on singledose pharmacokinetics of gabapentin capsules in healthy subjects. Pharm Res 1992;9:S315.
28. Lenth, R.V. (2006). Java applets for power and sample size [computer software]. Retrieved May, 8, 2011. [available from http://www.stat. uiowa.edu/ rlenth/Power]

29. Kaya FN, Yavascaoglu B, Baykara M, Altun GT, Gulhan N, Ata F. Effect of oral gabapentin on the intraocular pressure and haemodynamic responses induced by tracheal intubation. Acta Anaesthesiol Scand 2008;52:1076-80.

30. Kumari I, Pathania VS. A prospective randomised double-blind placebo controlled trial of oral gabapentin in attenuation of haemodynamic responses during laryngoscopy and tracheal intubation. J Anaesth Clin Pharmacol 2009;25(4):439-43.

31. Bafna U, Goyal VK, Garg A. A comparison of different doses of gabapentin to attenuate the haemodynamic response to laryngoscopy and tracheal intubation in normotensive patients. J Anaesth Clin Pharmacol 2011;27(1):43-6.

32. Seib RK, Paul JE. Preoperative gabapentin for postoperative analgesia: a meta-analysis. Can J Anesth 2006;53:461-9.

33. Omran AF, Mohamed AER. A randomized study of the effects of gabapentin versus placebo on post-thoracotomy pain and pulmonary function. Eg J Anaesth 2005;21:277-81.

34. Turan A, Karamanlioglu B, Memis D, Hamamcioglu MK, Tukenmez B, Pamukcuz $Z$ et al. Analgesic effects of gabapentin after spinal surgery. Anesthesiology 2004;100:935-8.

35. Figueredo E, Fuentes EMG. Assessment of the efficacy of esmolol on the haemodynamic changes induced by laryngoscopy and tracheal intubation: A meta-analysis. Acta Anaesthesiol Scand 2001;45:101122.

36. Gupta A, Wakhloo R, Gupta V, Mehta A, Kapoor BB. Comparison of esmolol and lidocaine for attenuation of cardiovascular stress response to laryngoscopy and endotracheal intubation. JK Science 2009;11:78-81.

37. Begum M, Akter P, Hossain MM, Alim SMA, Khatun UHS, Islam SMK et al. A comparative study between efficacy of esmolol and lignocaine for attenuating haemodynamic response due to laryngoscopy and endotracheal intubation. Faridpur Med Coll J 2010;5(1):25-8. 